\title{
Equity and Safety in Polar Oceanography? Let's Start with Equal Chances of Survival. Literally.
}

\author{
By Anna Glüder
}

As seagoing Earth scientists, we are used to taking safety procedures, safety training, and safety equipment very seriously. Understandably so: working on ships in remote regions means that accidents have the potential to be life-threatening. As a result, the precautions taken to minimize the risks of hazards are intended to be detailed and comprehensive.

Here, I highlight an opportunity for leadership to extend this strong advocacy for safety during field operations to an area that has historically been neglected: consideration of body sizes other than the "standard male" when equipping research ships with survival equipment.

Immersion suits, flight suits, life jackets, and foul weather gear are commonly stocked as one-size-fits-all. For me, a $160 \mathrm{~cm}$ ( $5 \mathrm{ft}, 3 \mathrm{in}$ ) tall woman, practice putting on an immersion suit aboard a ship usually triggers well-intentioned jokes about how it could fit several people my size rather than questioning whether in case of a true emergency I would be adequately protected. In the words of a mate of a major research ship who recently provided training on how to don the immersion suits: "We have the standard suits, and then some larger ones and a few extra-large ones. If you are small, sorry, they are probably not going to work that well."

They are not going to work that well. In Arctic waters, your survival chance without any protection is less than 15 minutes. Immersion suits are rated to prolong that time span to up to six hours, given a water-tight seal around wrists and neck and an ideal trim (good fit) after most of the air is purged from the suit.
The University-National Oceanographic Laboratory System (UNOLS) safety standards state that "immersion suits are required for vessels operating north of 32 degrees north and south of 32 degrees south and should be type approved under series 46 CFR 160.171" (UNOLS, 2015, p. 17-2). The US Code of Federal Regulations (CFR), 46 CFR 160.171-17 specifies that in order to be approved, general testing has to be conducted on three females and seven males of three physical body types. Required tests include donning time, field of vision, walking, climbing, righting, and water and air penetration. Testing related to thermal protection is listed separately and specifically calls for male test subjects to be used. Why has this testing not been updated to account for women's body types?

The International Convention for the Safety of Life at Sea (SOLAS) adopts regulations following resolution Msc.81(7), which are slightly different and require at least one of six test persons to be a woman (IMO, 1998). However, in order to test thermal protections, manikins can be used that represent the $50^{\text {th }}$ percentile North American male.

For both UNOLS and SOLAS, the required thermal protection states that the wearer's body temperature may not drop by more than two degrees when immersed for six hours in water between $0^{\circ}$ and $2^{\circ} \mathrm{C}$. The studies on which these and other legal requirements are based were conducted on-yes-male volunteers or manikins representing the $50^{\text {th }}$ percentile North American male (Tipton, 1995; Lewandowski and Clark, 2016). These immersion suit tests con- trast with the initial studies determining the rate of heat loss in Arctic waters without any protection, which featured both males and females (Hayward et al., 1975; Hayward, 1984).

Not only are the requirements for survival suits vague, current studies appear to have skipped even considering what equipment would be safe for anyone other than the $50^{\text {th }}$ percentile male. Perhaps this oversight led to blog posts such as this one, written from D/V JOIDES Resolution where immersion suits are supplied in four different sizes, including a small one: "There are four basic sizes-small, medium, large and extra-large. Those of us on the smaller end of small, however, are doomed to surviving without seeing-the zipper comes up level with our foreheads" (https://joidesresolution. org/survival-suit-101/).

A suit that is too large will fail in multiple ways. The most critical function of immersion protective clothing is to keep the clothing worn beneath them dry. Tipton (1995) shows that the critical limit of cold-water intrusion before a significant reduction of survival time is $200 \mathrm{ml}$ (i.e., not quite a cup). It's easy to see that an ill-fitting seal at neck and wrists can be deadly.

A second path to failure is the addition of buoyancy in the attached boot space. Most immersion suits are outfitted with an internal life jacket designed to keep the head above water to prevent drowning. To work properly, as much air as possible must be expelled from inside the suit when donning. The more space there is, the more difficult it is to push out all the extra air, which in a worst-case scenario, 
accumulates in the boot space, turning the person trying to survive head down in the water.

The prevalence of ill-fitting personal protection equipment has a second less extreme but more prevalent side effect than drowning: it makes many of us feel that we do not belong. I first considered this angle when, for the first time, I was wearing a flight suit for helicopter operations that was actually designed to fit me. Not only did it give me confidence that I was wearing the gear for its actual purpose rather than for somebody to fill a bureaucratic safety checkbox, it made me feel a true part of the operation rather than an afterthought.

One-size-fits-some-of-the-population means that once a standard uniform is issued, some of us look like professionals while others of us look like we borrowed dad's work outfit. We need to promote community discussion about our cultural assumptions regarding what is "standard." How can we ensure that those who do not fit this norm feel welcome in the Earth sciences rather than feel as if they are intruding upon somebody else's space?

Grant agencies, universities, and research vessel operators and organizations must ensure that in case of an accident, survival chances for all participants are equal. It's not radical to expect that survival gear on research ships should fit scientists no matter what shape or height they are. This is a very low bar to clear when it comes to creating a safe work environment for all. Let's make sure we clear it swiftly. As a community, we should not accept the risks of potentially failing safety gear for scientists who do not fall within the standard definition of the $50^{\text {th }}$ percentile North American male. @

\section{REFERENCES}

Hayward, J.S., J.D. Eckerson, and M.L. Collis. 1975. Thermal balance and survival time prediction of man in cold water. Canadian Journal of Physiology and Pharmacology 53:21-32, https://doi.org/10.1139/y75-002.

Hayward J.S. 1984. Thermal protection performance of survival suits in ice-water. Aviation, Space, and Environmental Medicine 55:212-215.
IMO (International Maritime Organization). 1998. Index of IMO Resolutions, http://www.imo.org/en KnowledgeCentre/IndexofIMOResolutions/Pages/ Default.aspx\#gsc.tab=0.

Lewandowski, M.J., and C.J. Clark. 2016. Immersion Suit Flotation Testing. REACT Report. Department of Homeland Security, Report No. CG-D-08-16, 17 pp. plus appendices, https://www.dcms.uscg.mil/ Portals/10/CG-9/RDTE/RDTE PDFs/CG-D-08-16. pdf?ver+2017-04-03-070333-920.

Tipton M.J. 1995. Immersion fatalities: Hazardous responses and dangerous discrepancies. Journal of the Royal Naval Medical Service 81: 101-107. UNOLS (University-National Oceanographic

Laboratory System). 2015. Research Vessel Safety Standards, $10^{\text {th }}$ ed. https://www.unols.org/sites/ default/files/RVSS_Edition_10_July2015.pdf.

\section{AUTHOR}

Anna Glüder (gluedera@oregonstate.edu) is a $\mathrm{PhD}$ candidate in the College of Earth, Ocean, and Atmospheric Sciences, Oregon State University, Corvallis, OR, USA.

\section{ARTICLE CITATION}

Glüder, A. 2020. Equity and safety in polar oceanography? Let's start with equal chances of survival. Literally. Oceanography 33(3):8-9, https://doi.org/10.5670/oceanog.2020.303.

\section{COPYRICHT \& USAGE}

This is an open access article made available under the terms of the Creative Commons Attribution 4.0 International License (https://creativecommons.org/ licenses/by/4.0/), which permits use, sharing, adaptation, distribution, and reproduction in any medium or format as long as users cite the materials appropriately, provide a link to the Creative Commons license, and indicate the changes that were made to the original content.

\section{อ}

The Council is the governing body of the Society. Voting in this election is an important function of membership. The persons elected will participate in directing the affairs and determining the future of the Society.

THE CANDIDATES. Candidates have been identified for the positions of President-Elect, Biological Oceanography Councilor, Education Councilor, and Physical Oceanography Councilor, and for three new positions - Early Career Councilor, Ocean Data Science Councilor, and Ocean Social Science and Policy Councilor. Brief biographical sketches for each of the candidates are available online at https://tos.org/council-election.

HOW TO VOTE. The TOS Council election is being conducted electronically. All TOS members were sent an email message from The Oceanography Society on December 1 at 6:00 pm EST containing a unique ballot link with a random, secret access key. If you are a TOS member and did not receive this message, please contact Jenny Ramarui, TOS Executive Director (jenny@tos.org or 301-251-7708) to receive voting instructions. All votes must be cast by January 31, 2021 (11:59 EST).
The Oceanography Society thanks the following for their time, dedication, and valuable contributions to the organization.

\section{Alan Mix}

Past President

Magdalena Andres Physical Oceanography

Charles Greene Biological Oceanography

Carolyn Scheurle

Education 